\title{
Turismofobia e os impactos econômicos do turismo nos discursos midiáticos do jornal "El País”
}

\section{Tourismphobia and the economic impacts of the tourism in the media speeches of the newspaper "El País"}

\author{
Giovanna Carvalho dos Santos ${ }^{1}$ \\ Frederico Ferreira de Oliveira ${ }^{2}$ \\ Jarlene Rodrigues Reis ${ }^{3}$
}

\begin{abstract}
Resumo - Tendo o espaço urbano como locus para sua concepção e seu desenvolvimento, o turismo gera diferentes formas de apropriação e de relacionamento com os lugares em que ocorre. Os impactos da atividade, tradicionalmente discutidos no âmbito acadêmico, gradativamente ganham eco em uma variedade de plataformas comunicacionais, em virtude da dimensão atribuída ao turismo por diversos grupos sociais. Os discursos midiáticos reproduzidos em jornais, na televisão e no cinema criam e reforçam sentidos ligados ao modo como se interpreta o fenômeno turístico, e nessa esfera ganham espaço termos e expressões com forte carga de significados, como a turismofobia. Partindo desse cenário, este trabalho tem como objetivo discutir as representações midiáticas do termo "turismofobia" nos discursos sobre os impactos econômicos do turismo identificados a partir de publicações do jornal espanhol El País, no período entre julho e agosto de 2017. A fim de explorar o conteúdo de cada publicação, foi realizada a análise da construção de tais conteúdos realizados pelos jornalistas, comparando-se os dados com o escopo conceitual da pesquisa. Os resultados estudados permitiram observar que o El País tem sido um espaço de destaque na criação de sentidos ligados à turismofobia como forma de manifestar, discursivamente, conflitos e contradições gerados a partir dos impactos econômicos do turismo na Espanha.
\end{abstract}

Palavras-chave: Turismo. Impactos econômicos; Turismofobia; Midiatização; El País

\footnotetext{
${ }^{1}$ Curso Superior de Tecnologia em Gestão de Turismo pelo Centro Federal de Educação Tecnológica Celso Suckow da Fonseca (Cefet/RJ - Campus Petrópolis). E-mail: gicarvalhosantos@gmail.com

${ }^{2}$ Mestrado em Administração e em Gestão Social, Educação e Desenvolvimento Local pelo Centro Universitário UNA. Bacharelado em Turismo pela Faculdade de Turismo de Santos Dumont (FACTUR). Professor do Curso de Bacharelado em Turismo do Cefet/RJ - Campus Petrópolis. E-mail: turofredfo@uol.com.br

${ }^{3}$ Mestrado em Administração pela Universidade Federal de Minas Gerais (UFMG). Bacharelado em Turismo Universidade Federal de Juiz de Fora (UFJF). Doutoranda em Comunicação pela Universidade do Estado do Rio de Janeiro (UERJ). Professora do Curso de Bacharelado em Turismo do Cefet/RJ - Campus Petrópolis. E-mail: jarlenerodrigues@yahoo.com.br
} 


\begin{abstract}
The tourism has as its main locus the urban space for its conception and development, generating different forms of appropriation and relationship with the places where it occurs. The impacts of the activity, traditionally discussed in the academic sphere, gradually gain echo in a variety of communication platforms, due to the dimension attributed to tourism by different social groups. The media speeches reproduced in newspapers, on television, in the cinema, create and reinforce meanings linked to the way the tourism phenomenon is conceived, and then the terms and expressions with a heavy load of meanings gain space, such as tourismphobia. Based on this scenario, this paper aimed to discuss the media representations of the term "tourismphobia" in the speeches concerning the economic impacts of tourism identified from publications of the Spanish newspaper El País, in the period between July and August of 2017. In order to explore the content of each publication, an analysis of the construction of such content carried out by journalists was accomplished, comparing the data with the conceptual scope of the research. The results allowed to observe that El País has been a prominent space in the creation of meanings linked to the tourismphobia as a way to manifest, discursively, conflicts and contradictions generated from the economic impacts of tourism in Spain.
\end{abstract}

Keywords: Tourism; Economic impacts; Tourismphobia; Media Speeches; El País. 


\section{INTRODUÇÃO}

Numa época em que as diferentes plataformas midiáticas disputam atenção e prometem oferecer conteúdos constantemente atualizados sobre os mais diversos temas, percepções e decisões individuais são influenciadas por textos, sons e imagens encontrados a partir de mecanismos de busca. A respeito das viagens, basta digitar o nome da destinação desejada em uma ferramenta virtual de busca e surgem sugestões de roteiros, pacotes, opiniões de visitantes anteriores e notícias sobre a localidade. Com base nesses conteúdos, formam-se percepções e opiniões sobre os lugares turísticos. Os discursos sobre o turismo refletem a dinâmica da própria atividade e suas relações socioculturais, econômicas e ambientais que acontecem, principalmente, nos espaços urbanos. Tal abrangência faz com que os impactos do turismo sejam igualmente amplos e continuamente projetados na esfera midiática.

Nesse sentido, Falco (2011) ressalta que o jornalismo promove importante função, relacionada à credibilidade que lhe é conferida pelo público. Ainda segundo a autora, sua ação se dá como uma espécie de narrativa do real e exerce representações sobre as cidades, povos e culturas, aos quais são conferidos imaginários e identidades que serão percebidos pelo leitor. A ascensão do termo "turismofobia" aconteceu justamente nesse cenário, em perspectiva jornalística e midiática, como termo que agrega um conjunto de significados ligados ao repúdio pelo turismo massificado e suas consequências negativas nas localidades (DOMÍNGUEZ, 2018).

Desde 2017 cidades como Barcelona, Lisboa, Atenas, Amsterdam e Roma estiveram entre as primeiras a identificar manifestações de turismofobia, a exemplo da expressão "Your luxury travel, my daily misery", muito propagada nessas cidades em cartazes ou intervenções urbanas de protesto, devido à insatisfação de parte da população diante dos efeitos da atividade turística. Em seguida, lugares menores como Santorini, Veneza e Malta também ganharam destaque em virtude do registro de conflitos ligados ao turismo e associados à turismofobia.

Nessas localidades, jornais e portais de notícias reproduzem as inquietações de moradores, empresários e dos próprios visitantes em relação à dimensão dos impactos do turismo. Na Espanha, o “El País”, um dos principais veículos de comunicação espanhóis, possui papel importante no que diz respeito à formação de opinião acerca das narrativas 
e repercussões midiáticas sobre a turismofobia nas cidades retratadas, ou seja, é um espaço expressivo para múltiplos debates em torno de suas supostas causas, e consequentemente, as reações de parte dos atores sociais e governamentais.

A turismofobia tem se destacado também em estudos que agregam diferentes áreas acadêmicas, dentre as quais as pesquisas desenvolvidas por Ruiz (2008), Milano (2017), e Domínguez (2018). Esses autores tratam a turismofobia como um fenômeno que segue o ritmo da massificação do turismo em cidades com alta demanda de visitação. Diante de tal contexto é que se pretende neste estudo discutir as representações midiáticas do termo "turismofobia" nos discursos sobre os impactos econômicos do turismo, identificados a partir de publicações do jornal espanhol El País que abordam a temática, no período entre julho e agosto de 2017. Tais construções reflexivas foram realizadas com base nas vertentes teóricas de autores das áreas de planejamento turístico, a exemplo de Swarbrooke (2000), Quintana (2006), Jafari (2000), Cooper et al. (2007) e midiatização, trabalhada por Sodré (2002), Gomes (2017) e Lafon (2019).

Dessa forma, o trabalho encontra-se estruturado em seções diferentes, sendo que na primeira abordam-se questões referentes aos impactos econômicos do turismo, bem como a turismofobia e seus aspectos conceituais. No que diz respeito à midiatização, a segunda seção apresenta uma reflexão sobre a função dos meios de comunicação como mediadores na concepção de sentidos e a sua influência nos processos de interação e midiatização social. A terceira seção dedicou-se à metodologia empregada para a pesquisa e o desenvolvimento do trabalho. Por fim, partindo da apresentação e da análise dos dados, na quarta seção investigou-se os meios de construção das narrativas jornalísticas e discursos midiáticos relacionados ao tema em discussão, além do modo como os editoriais do jornal El País estão atrelados direta ou indiretamente aos impactos econômicos da atividade turística nas cidades espanholas.

A partir da discussão proposta na pesquisa, pretende-se contribuir para que se conheçam mais amplamente as articulações entre os discursos midiáticos e a atividade turística, em especial aqueles relacionados à projeção dos impactos econômicos do turismo na mídia e na percepção de moradores das localidades turísticas. 


\section{A TURISMOFOBIA COMO REFLEXO DOS IMPACTOS ECONÔMICOS DO TURISMO}

Não obstante as muitas razões demonstradas e bem-intencionadas que envolvem o desenvolvimento do setor turístico, a exemplo das originadas na Declaração de Manila em outubro de 1980 (OMT, 2019), são as vantagens econômicas que proporcionam as principais diretrizes em prol do crescimento da atividade. Os benefícios relacionados à geração de divisas estrangeiras, renda e empregos geralmente são os estímulos para uma localidade investir na inclusão do turismo como uma importante estratégia de desenvolvimento.

Swarbrooke (2000) acrescenta que o turismo é a base do progresso de empresas multinacionais, integrando de forma significativa e anual a renda da grande maioria da população nos países desenvolvidos; como também é responsável pelo avultado investimento na ordem de bilhões dos cofres públicos todos os anos, vista a necessidade de incrementos em infraestrutura em prol da atividade turística e do turista.

De fato, a capacidade das atividades turísticas em fomentarem a criação de empregos e o crescimento econômico faz com que também sejam reconhecidos e ajustados os níveis de comprometimento e encorajamento no que diz respeito à proteção do meio ambiente e do patrimônio cultural nas destinações turísticas, bem como o fortalecimento dos laços entre os povos.

Segundo Jurdao (1992), nas primeiras etapas do turismo de massa, o conceito generalizado era de que a atividade apresentava potencial de crescimento ilimitado, sobretudo no viés econômico, em realidades mais e menos desenvolvidas.

A partir desta perspectiva, durante o século XX, diversos países apostaram no turismo como alternativa de desenvolvimento socioeconômico. Instituições como a Organização de Cooperação e de Desenvolvimento Econômico - OCDE, o Banco Mundial e as Nações Unidas inclusive instauraram o ano de 1967 como sendo o "Ano Internacional do Turismo".

Contudo, como assinala Quintana (2006), apesar do grande potencial turístico, diversos países negligenciaram estudos prévios quanto ao planejamento em longo prazo. Segundo a autora, o conceito triunfal do turismo expandiu-se, entretanto, mais tarde surgiriam as consequências em algumas zonas do mundo. 
A partir dos anos 1980, os estudos científicos e reflexões em torno dos impactos causados pela atividade turística face aos aspectos socioculturais, socioeconômicos e ambientais começaram a repercutir. Nesse contexto, Jafari (2000) considera que os efeitos relacionados ao turismo devem ser averiguados com base nas vertentes de "defesa" e "aviso", a primeira no que concerne aos benefícios da atividade, e a segunda no âmbito de ponderar eventuais riscos e custos decorrentes da insuficiência, ou por vezes ausência de planejamento turístico da localidade.

A importância na diferenciação de tais aspectos se dá ao nível de exigência das abordagens metodológicas, isto é, ao calcular o impacto econômico das despesas turísticas, utiliza-se a análise do princípio do "efeito multiplicador", que Swarbrooke (2000, p.96) define como "[...] a ideia de que o dinheiro gasto pelos turistas circula pela economia local em uma série de ondas".

Isso posto, Cooper et al. (2007, p.179) enfatizam a capacidade do turismo em fomentar um "[...] efeito cascata em toda economia receptora $[\ldots]$ ", e em outras atividades econômicas relacionadas de forma direta ou indiretamente ao setor, a exemplo da agricultura, construção civil e indústria (alimentos e bebidas, têxtil, mobiliária, etc).

A fim de sintetizar a discussão dos impactos econômicos por meio da visão dos autores, foi organizado o Quadro 1, para que se possa distinguir entre os possíveis impactos gerados pela atividade turística.

\section{QUADRO 1- IMPACTOS ECONÔMICOS DO TURISMO}

\begin{tabular}{|c|c|}
\hline Impactos positivos & Impactos negativos \\
\hline Geração de empregos a diversos níveis; & Empregos mal remunerados e/ou sazonais \\
\hline $\begin{array}{l}\text { Injeção de renda na economia local em razão dos } \\
\text { efeitos multiplicadores contribui para a } \\
\text { formação do PIB do país; Melhoria da } \\
\text { acessibilidade e redes de mobilidade urbana. }\end{array}$ & $\begin{array}{l}\text { Custos de ocasião, ex.: dinheiro investido em } \\
\text { turismo ter seu uso inviabilizado em investimentos } \\
\text { futuros; Tendências inflacionistas a nível local, } \\
\text { regional. }\end{array}$ \\
\hline $\begin{array}{l}\text { Auxílio para a manutenção da viabilidade dos } \\
\text { negócios locais. }\end{array}$ & Congestionamento; Especulação imobiliária. \\
\hline $\begin{array}{l}\text { Reestruturação do equilíbrio da economia em } \\
\text { cidades e metrópoles onde outras atividades } \\
\text { industriais estão em declínio; Atração de } \\
\text { investimento estrangeiro. }\end{array}$ & $\begin{array}{l}\text { Necessidade de investir em infraestrutura } \\
\text { dispendiosa que pode ser usada apenas em parte do } \\
\text { ano; Flutuações sazonais e descontinuidade da } \\
\text { atividade turística. }\end{array}$ \\
\hline $\begin{array}{l}\text { Estímulo ao desenvolvimento rural e regional, } \\
\text { reformando áreas urbanas e diversificando as } \\
\text { economias locais. }\end{array}$ & $\begin{array}{l}\text { Excessiva dependência do turismo, tornando a } \\
\text { economia do local vulnerável. }\end{array}$ \\
\hline $\begin{array}{l}\text { Contribuição para a melhoria do equilíbrio das } \\
\text { contas externas de um país. }\end{array}$ & $\begin{array}{l}\text { Migração de mão de obra de áreas rurais para áreas } \\
\text { urbanas, ocasionando escassez de mão de obra } \\
\text { qualificada. }\end{array}$ \\
\hline
\end{tabular}

FONTE: Elaboração própria a partir de Beni (2007); Cala et al. (2006); Cooper et al. (2007); Swarbrooke, (2000) 
É importante ressaltar que os impactos relacionados no Quadro 1 não estão vinculados entre si, isto é, a coluna de impactos positivos não está relacionada com a de impactos negativos diretamente, ambas demonstrando as diferentes visões a respeito da temática em discussão.

Os impactos econômicos do turismo em uma localidade geralmente são positivos, contudo, há também diversos aspectos negativos, cuja natureza varia entre diferentes destinações. Cooper et al. (2007), por sua vez, acrescentam que a literatura existente ainda apresenta uma visão preconceituosa em relação aos aspectos positivos dos impactos econômicos. Ademais, os autores destacam a importância do estabelecimento do real significado dos gastos com o setor turístico para uma economia, devido ao fato de permitir aos formuladores de políticas que definem a linha de ação e, aos que planejam o setor, determinar a dependência e desenvolver estratégias sustentáveis e em longo prazo.

Por sua vez, Swarbrooke (2000) exemplifica essas ações como: garantir os benefícios do turismo para com toda a comunidade local, principalmente entre as esferas da população economicamente menos favorecidas; desenvolver formas de turismo que otimizem seus benefícios econômicos; assegurar que o turista pague um preço justo por sua experiência de férias; certificar que as empresas locais possam estar protegidas da concorrência desigual das grandes empresas estrangeiras que possuem pouco compromisso com a sustentabilidade da destinação; agir no tocante a divisão imparcial entre a indústria do turismo e os órgãos governamentais locais, os custos para atrair turistas e satisfazer suas necessidades; e reduzir a fuga de capital da economia local.

Contudo, Swarbrooke (2000) esclarece que a implementação rigorosa de tais ideias pode acarretar a um protecionismo e o subsequente monopólio das empresas locais frente aos turistas. Portanto, há de se atingir o equilíbrio entre o controle local, mercado livre e a escolha do consumidor.

Na visão de Murta e Albano (2002), o turismo como atividade econômica requer, no entanto, mensurar as alternativas encontradas ao se inserir no dia a dia das populações receptoras. Torna-se fundamental que os investimentos se adequem à vocação dos destinos, proporcionando a participação ativa e desfrute da população, bem como o desenvolvimento local sustentável. 
A turismofobia é um dos fenômenos recentes que mais tem chamado a atenção de estudiosos da área de turismo como Milano (2017), autoridades e sociedade civil, gerando manchetes e discussões em todos os recursos midiáticos possíveis, esferas sociais e campos de investigação, bem como equívocos referentes ao termo overtourism.

A princípio, o termo "turismofobia" se refere ao resultado da pressão social ocasionada pela ineficiência ou inexistência de planejamento turístico e/ou urbano em um destino, deixando claro os impactos negativos acarretados pela atividade turística, e consequentemente desvirtuando o olhar dos residentes sobre os aspectos positivos.

As discussões envolvendo tanto a "turismofobia" quanto o overtourism, embora sejam termos que possuam relação entre si, são desencadeadas de forma distinta pelos meios de comunicação. O overtourism se aproxima das discussões relacionadas à crescente evolução da pressão turística nas localidades. No que se refere à "turismofobia", o termo apresenta conotação negativa, uma vez que "fobia", de acordo com o dicionário Michaelis (2018), é entendida como o medo mórbido, exagerado; falta de tolerância, aversão, rejeição.

Para Milano (2017), a generalização do termo é resultado do, talvez ambíguo, uso por parte da mídia para descrever o descontentamento social que surgiu em resposta ao overtourism. Ou seja, na visão do autor, ao "patologizar essa agitação social", há a desvalorização das críticas e dos movimentos sociais pautados em políticas públicas sustentáveis de turismo.

Desse modo, para a Fundación del Español Urgente (Fundéu-BBVA), instituição assessorada pela Real Academia de Língua, a turismofobia pode ser reconhecida como o neologismo pertinente ao uso especificamente midiático, para atribuir significado "ao repúdio pela turistificação", outro neologismo de interpretação que pode ser descrito como "[...] modelo turístico caracterizado pela massificação e suas consequências negativas para a população e os trabalhadores" (DOMÍNGUEZ, 2018, p.23).

Os primeiros esboços sobre a efervescência da turismofobia nos dias atuais já podiam ser percebidos há uma década, no editorial assinado pelo antropólogo Manuel Ruiz (2008) e publicado no jornal El País, cujo título “Turistofobia” é usado como um neologismo para sugerir "uma espécie de xenofobia de substitutiva", "misto de repúdio, desconfiança e desprezo" pela figura do turista. Ruiz (2008) enfatiza a questão da "monocultura turística", que privilegia o setor e negligencia a necessidade de manter a 
qualidade de vida da população local. Na perspectiva do autor, “O problema não é que há turistas, mas sim apenas turistas. Não é o turismo que esvaziou os centros históricos de sua história e de seu povo, mas a gestão da cidade como um negócio e como dinheiro" (RUIZ, 2008, s/p).

Para Milano (2017), o termo "turismofobia" teve origem ainda de forma sutil, em reportagens constantes sobre o descontentamento social em relação ao aumento de turistas em cidades europeias, em que o uso indiscriminado do termo, na opinião do autor, expôs de forma inadequada a emergência em torno da massificação turística.

Desde então, tais manchetes se estenderam a localidades como Dubrovnik, Veneza, Amsterdam, Lisboa, e Barcelona, onde o fenômeno ganhou destaque na imprensa internacional, e de acordo com o jornal espanhol El País o setor tem lidado com certa inquietação com o aumento da rejeição ao turismo.

A partir dessa discussão sobre impactos econômicos e constructos da turismofobia, o próximo tópico terá como enfoque a comunicação, mais especificamente o conceito de midiatização para a contextualização dos impactos do turísticos a partir de textos jornalísticos.

\section{A MIDIATIZAÇÃO COMO FORMA DE REPRESENTAÇÃO DO MUNDO}

O período hoje reconhecido como "contemporâneo" é marcado por uma espécie de transição epocal, caracterizada por uma sociedade cada vez mais midiatizada, delineada por novas formas de ser e de estar no mundo para além da interação por intermédio das tecnologias, um verdadeiro "bios midiático" reconfigura o tecido e as relações sociais (SODRÉ, 2002; GOMES, 2017).

Para Sodré (2006), na medida em que serve como elemento balizador de novas moralidades e sentidos de ética, a mídia se estrutura como esfera existencial determinante da organização de sentidos e papéis sociais. Por conseguinte, a midiatização se caracteriza pela "virtualização das relações humanas, presente na articulação do múltiplo funcionamento institucional e de determinadas pautas individuais de conduta com as tecnologias da comunicação" (SODRÉ, 2006, p. 20).

Ainda para o autor, que parte de uma perspectiva aristotélica, a midiatização consiste numa espécie de "quarto bios", isto é, mais um âmbito existencial, ao lado da 
vida contemplativa, da vida prazerosa e da vida política. Pressupõe-se não somente a influência direta e indireta da mídia sobre a vida real, mas adequam-se as experiências pautadas na lógica imposta pelo “bios midiático”. Sodré (2002) conclui que o poder e os efeitos desencadeados pela influência da mídia, seja a tradicional (meios de comunicação impressos, rádio e televisão) ou a digital (internet, mídias sociais virtuais), podem ser considerados na verdade, como a ideia central que envolve toda a sociologia e antropologia da comunicação contemporânea. $\mathrm{O}$ autor destaca que a maior parte das pesquisas sobre influência e efeitos realizadas até os dias atuais tem levado à conclusão de que a mídia é parte estruturante ou reestruturante de cognições e percepções, exercendo o papel de uma espécie de "agenda coletiva".

Muito embora existam linhas de pensamento que definem a midiatização como mediação tecnológica, Gomes (2017) enfatiza que a sociedade está diante de algo novo, que promove um salto qualitativo no que diz respeito ao avanço da mídia. O autor também ressalta que a midiatização se reconfigura como mais um âmbito existencial, isto é, o bios midiático, o que vem a ser um princípio, modelo, e, consequentemente, a chave para a interpretação e a compreensão da realidade. Os indivíduos identificam e se identificam por intermédio da mídia, agora com recursos alargados que vão além dos dispositivos tradicionais. Diante disto, para Gomes (2017), é possível mencionar a mídia como um locus de discernimento da sociedade.

Contudo, como ressalta Lafon (2019), a midiatização não se aplica igualmente a qualquer ocorrência social, mas apenas a determinados eventos. Isso significa que, para os jornalistas, por exemplo, um fato merece ou não a abordagem midiatizada, dependendo do quanto é insólito ou inédito. Da mesma forma, continua o autor, a midiatização constitui um campo para que os sujeitos se posicionem social e politicamente, reproduzindo suas disputas simbólicas e suas relações de força. Trata-se de conferir visibilidade a determinadas posições e opiniões, refletindo em todos os domínios da vida social (LAFON, 2019). Portanto, o processo de midiatização pressupõe o estabelecimento de acordos e trocas que determinam os papéis desempenhados pelos diferentes sujeitos sociais que se alinham às dinâmicas midiáticas de interação, concorrendo para o surgimento de novas experiências de sociabilidade, como é o caso das viagens.

Ainda no bojo das interações sociais midiatizadas e dos conflitos que daí decorrem, Paiva (2012, p. 153) observa uma importante contradição pois, ao mesmo 
tempo que a midiatização se propõe "aberta, transparente, democrática, [...] é atravessada por forças econômicas, políticas, institucionais que a impelem numa direção contrária”. A midiatização não garante igualdade no exercício dos atos comunicacionais, nem em termos simbólicos tampouco no acesso aos dispositivos que potencializam certas práticas de interação, como a internet em banda larga. Pensando, portanto, nas mídias como operadoras de sentido e facilitadoras de acordos e trocas de trabalho colaborativo, levamos em conta que elas incorporam tensões sociais e interesses assimétricos nos processos de comunicação observados a partir da emergência de fenômenos sociais tão complexos como a turismofobia.

Nessa perspectiva, faz-se imprescindível a reflexão sobre a função dos meios de comunicação como mediadores na concepção de sentido da vida para as pessoas, que, ao se relacionarem com o mundo, interagem entre si com o intuito de se localizarem no espaço e no tempo. No campo do turismo, esses meios atuam diretamente na produção de sentidos e imaginários sobre espaços urbanos e lugares, como tem acontecido no caso do uso e representações midiáticas do conceito de turismofobia.

Assim, é preciso compreender como nas narrativas do jornal El País sobre as cidades espanholas citadas, é retratado o relacionamento entre turismo e moradores locais, a partir dos possíveis impactos que são gerados e por vezes tensionados pela mídia jornalística, temática essa que será tratada a seguir.

\section{PERCURSO METODOLÓGICO}

Tendo por base o objetivo e a temática abordada nesta investigação, desenvolveuse, além da pesquisa bibliográfica, a coleta de dados durante os meses de julho e agosto do ano de 2017, no portal digital do jornal espanhol El País. Para melhor compreensão dos conteúdos, foi utilizada ao longo do texto a tradução literal do idioma espanhol para o idioma português de todos os títulos e trechos das publicações analisadas, realizada livremente pelos autores do trabalho.

Dentre outros veículos de comunicação espanhóis, o jornal El País possui o papel de vanguarda no que diz respeito às publicações sobre a turismofobia na cidade de Barcelona, cedendo espaço significativo em seu periódico para múltiplas discussões em torno de seus aspectos, efeitos, e as reações de parte da sociedade e do poder público, o 
que notoriamente reflete na forma como a midiatização tem dado visibilidade para tal aspecto negativo do turismo em destinos turísticos da Europa.

A busca na plataforma online do jornal se deu por meio do recorte analítico das matérias a partir de palavras chave como "turismofobia", "turistificação", "turismo massivo", "economia urbana" e, "gentrificação", tendo como resultado 19 publicações a serem analisadas. Em sequência, tais publicações foram selecionadas, armazenadas em documento Word, e posteriormente ordenadas de forma cronológica, com ênfase em acontecimentos da capital catalã.

A escolha do período (mês) e do respectivo ano para a realização da pesquisa se deu em virtude de sua relevância, devido à ocorrência de fatos e eventos relacionados à emergência de discursos associados à turismofobia, em especial na Espanha. Destacamse, nesse sentido, incidentes envolvendo conflitos entre visitantes e moradores locais durante a temporada do verão europeu de 2017, bem como a repercussão e a popularidade da palavra "turismofobia" no mesmo período na Espanha, conforme apresentado na Figura 1 por meio da pesquisa realizada na ferramenta de termos e buscas populares, Google Trends.

FIGURA 1 - EVOLUÇÃO DA PESQUISA PELO TERMO “TURISMOFOBIA” NO ANO DE 2017

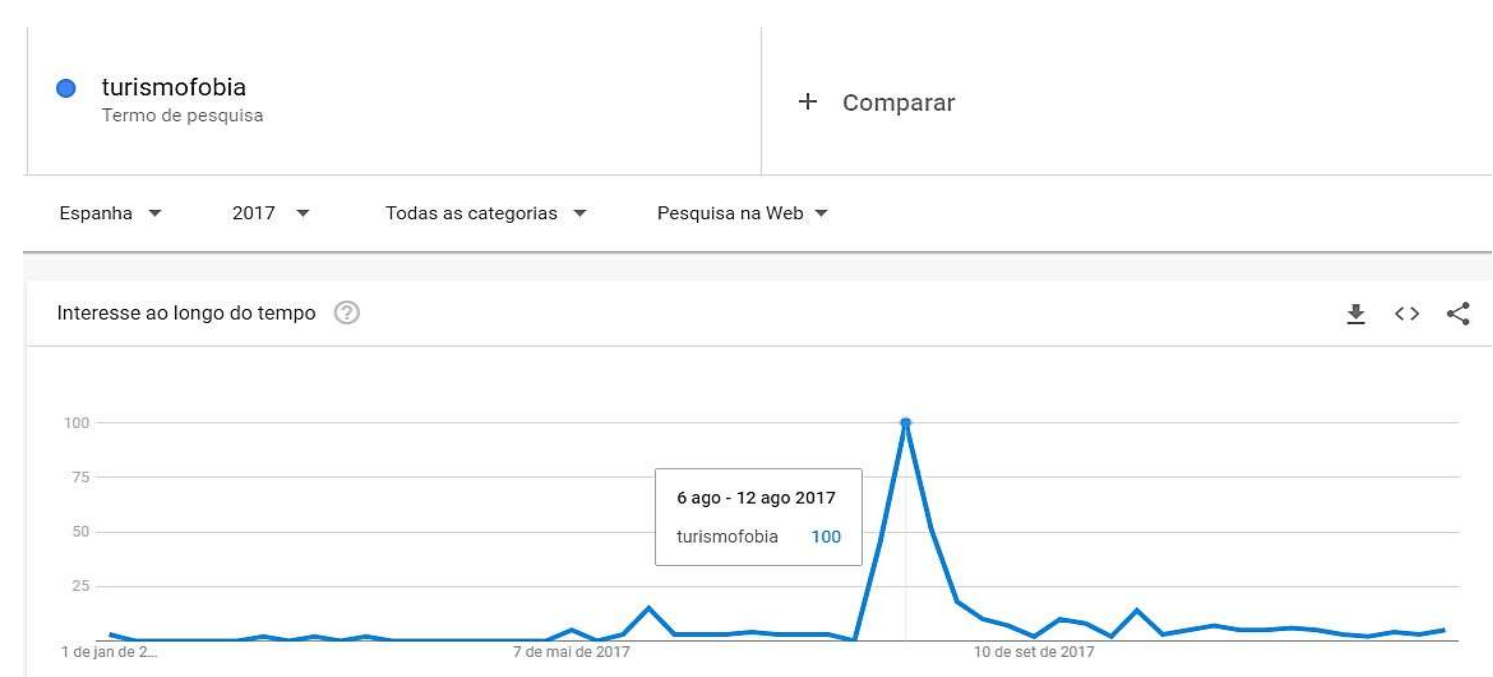

FONTE: Google Trends

Os dados coletados, contemplando as publicações do jornal em El País contempladas durante os meses julho e agosto de 2017, estão sintetizados no Quadro 2, 
que reúne as datas e títulos das matérias analisadas. Ao longo do trabalho, as citações diretas dos conteúdos das matérias estão apresentadas no idioma português, após tradução livre realizada pelos autores.

\section{QUADRO 2 - TÍTULOS DAS PUBLICAÇÕES DO PORTAL DIGITAL DO JORNAL EL PAÍS SOBRE A TEMÁTICA TURISMOFOBIA}

\begin{tabular}{c|l}
\hline 30 de julho & Un grupo de la izquierda independentista asalta un bus turístico en Barcelona \\
\hline 31 de julho & ¿Turismofobia o empleofobia? \\
\hline 04 de agosto & La turismofobia suma a los radicales vascos \\
\hline 05 de agosto & Los turistas no perciben los ataques como amenaza \\
\hline 05 de agosto & "Ahora frenamos aquellos excesos" \\
\hline 05 de agosto & Turismofobia, ciudades del alquiler \\
\hline 07 de agosto & Ada Colau dice que los autores de los ataques turísticos responderán ante la justicia \\
\hline 07 de agosto & Hoteleros de Barcelona piden contundencia contra la turismofobia y los pisos ilegales \\
\hline 07 de agosto & Colau no tomará ninguna medida contra la turismofobia \\
\hline 08 de agosto & Barcelona es el primer mercado de España para Airbnb \\
\hline 12 de agosto & Ciudadanos y hoteleros piden al PP regular los pisos turísticos \\
\hline 12 de agosto & Los vecinos de la Barceloneta toman la playa en contra de los excesos del turismo \\
\hline 13 de agosto & Inquietud en el Reino Unido ante los brotes de turismofobia en España \\
\hline 14 de agosto & Instrucciones para sobrevivir con demasiados turistas a tu alrededor \\
\hline 14 de agosto & ¿Cuántos turistas caben en España? \\
\hline 16 de agosto & "Lo que hay detrás de la hostilidad al turismo es xenofobia" \\
\hline 17 de agosto & Los radicales vascos dicen en San Sebastián que su lucha "no es turismofobia" \\
\hline 19 de agosto & El atentado en Barcelona golpea al sector turístico en pleno debate sobre sus límites \\
\hline 27 de agosto & Turismo amenazado \\
\hline
\end{tabular}

\section{FONTE: Elaboração própria}

Por meio do levantamento inicial, observou-se que as ideias de disputas territoriais, conflitos socioculturais e socioeconômicos entre turistas e moradores locais, além de constantes questões que englobam consternações referentes às esferas da gestão pública e privada, eram frequentes nos conteúdos analisados. A partir dessas ideias, construíram-se quatro categorias de análise: "Relações conflituosas entre moradores locais e turistas nas narrativas midiáticas do El País", "Economia local, impactos e as relações divergentes com a atividade turística segundo o jornal El País", "Território, meio ambiente, e suas construções discursivas no jornal El País", e "Os desdobramentos midiáticos da turismofobia no El País". 
De acordo com o que foi discutido acima, nas seções seguintes serão apresentadas as análises dos dados coletados, além de articulações com os impactos socioculturais do turismo e a midiatização, que remetem ao que foi discutido no referencial teórico da pesquisa, com um enfoque nas percepções relacionadas aos impactos econômicos.

\section{RESULTADOS}

A respeito dos impactos relacionados à economia, as reportagens do dia 31 de julho (“Turismofobia ou empregofobia?"), 5 de agosto (“Agora freamos aqueles excessos"), 13 de agosto ("Inquietação no Reino Unido ante aos surtos de turismofobia na Espanha"), e 27 de agosto ("Turismo ameaçado"), apresentam trechos que refletem contundentes questões relacionadas às despesas turísticas e ao desenvolvimento econômico da atividade.

Como exemplo, podem-se observar trechos da matéria "Agora freamos aqueles excessos", que trata da influência dos Jogos Olímpicos de Verão de 1992 realizados em Barcelona, na região da Catalunha, na promoção do setor turístico pré, durante, e após o megaevento. Nessa reportagem chama atenção o trecho em que o arquiteto e diretor do plano urbanístico de Barcelona diz:

\footnotetext{
Antes de 1992 em Barcelona, vivíamos em paz. Os jogos colocaram a cidade no mapa [...] Eles concentraram todo o esforço econômico em apenas uma perna: o turismo. O mais irônico é que agora estamos trabalhando para acabar com os excessos que nos levam a receber milhões de visitantes. [...] nos últimos dez anos houve um rebote selvagem de turistas que representa um conflito no uso do espaço público. (CONGOSTRINA, 2017).
}

A reportagem "Turismofobia ou empregofobia?", por sua vez, apresenta um fragmento que remete a questão do desenvolvimento repentino e sem controle da atividade turística em um destino, que hoje é uma das causas para os manifestos de moradores contra o modelo adotado em Barcelona:

Lembrem aos turistas e aqueles que praticam a violência contra moradores e turistas, que há três décadas Barcelona optou por se abrir para o mundo: quase não havia visitantes. Hoje, o setor responde por $12 \%$ do PIB da cidade. Gera $20 \%$ dos novos empregos na Espanha. [...] Turismofobia mata empregos. (EL PAÍS, 2017).

Os relatos retratam um dos impactos mencionados por Swarbrooke (2000), referindo-se à excessiva dependência do setor econômico ao turismo. Além disso, 
resgatam para a prática o entendimento de Cooper et al. (2007), ao destacarem a importância do estabelecimento e do planejamento dos gastos para o setor turístico em uma economia. Tais ações permitem o desenvolvimento e a formulação de estratégias em longo prazo, que podem auxiliar na estabilidade do setor em períodos sazonais, contribuindo para reduzir os impactos de agentes externos, a exemplo de atos de terrorismo e da própria turismofobia.

Entretanto, observa-se o viés das narrativas midiáticas das reportagens, a divulgação de imagens dos atos contra a atividade turística, de muros com frases que repudiam os turistas, ou atos que parcialmente possam envolver a turismofobia e seus efeitos. As matérias analisadas passam a ideia de que possa haver relação entre os discursos reproduzidos midiaticamente e o aumento desses incidentes, pois ao reforçar o imaginário e a percepção negativa do leitor, legitima-se a retórica frequentemente relacionada à turismofobia por parte dos cidadãos e dos futuros visitantes.

No viés econômico, seguindo a linha de pensamento de Swarbrooke (2000) e Cooper et al. (2007), há o trecho de outra matéria, "Turismo ameaçado: Os atentados podem afetar um setor essencial que deve se proteger", em que o jornalista destaca:

[...] não é de forma alguma um setor livre de ameaças [...] A deterioração da qualidade da oferta é uma delas, mas também a escassa diversificação desse binômio "sol e praia baratos" [...] Os terríveis ataques terroristas na Catalunha são mais do que apenas um aviso sobre a vulnerabilidade da bonança do setor. Esta comunidade autônoma é a principal receptora de turistas estrangeiros [...] A Espanha tem capacidade empreendedora e atributos culturais, históricos e gastronômicos para colocar sua oferta em níveis suscetíveis de gerar maiores receitas com menores custos para todos, mas sem gerar aversão aos visitantes. (EL PAÍS, 2017).

No tocante à qualidade da oferta dos serviços turísticos, a falta de diversificação de mercado descrita na reportagem, e a vantagem competitiva do turismo "sol e praia", podem comprometer a diminuição da massificação de um destino, a geração de empregos não sazonais e bem remunerados, e o equilíbrio da economia regional. Segundo Swarbrooke (2000) a natureza do turismo na destinação é um dos fatores cruciais para determinar o caráter dos impactos sofridos em uma localidade.

A metodologia do "efeito multiplicador", empregada por Swarbrooke (2000) para calcular o impacto econômico das despesas turísticas e a análise com base nas vertentes “defesa” e "aviso" defendida por Jafari (2000) podem ser úteis para desenvolver tipos de turismo que otimizem os benefícios econômicos e minimizem os custos para o destino, 
ao mesmo momento que também podem proporcionar vantagens advindas da atividade turística para toda a comunidade local, principalmente entre núcleos da população menos favorecidos economicamente.

Em contraponto, o editorial do El País do dia 13 de agosto, "Inquietação no Reino Unido ante aos surtos de turismofobia na Espanha", pretende retratar a perspectiva otimista diante aos constantes episódios de turismofobia ocorridos no período de agosto de 2017 na Espanha. Segundo o jornal, agências de viagem europeias não constataram impactos nas vendas e na demanda, e ainda consideram o destino como sendo estável e seguro. Trechos da matéria ressaltam:

[...] Não dá uma boa imagem, mas é marginal [...] A Associação de Operadores Turísticos Britânicos (ABTA, na sigla) acendeu todos os alarmes com a notícia sobre a Espanha, apesar de que, neste momento não têm tido efeito na a alta demanda, e recomenda aos seus clientes a ter "bom senso, fique atento e evite visitar locais que possam representar risco." [...] "Não notamos nenhum impacto" diz o porta voz da operadora Thomas Cook [...] No ano passado, 11 milhões de turistas alemães viajaram para a Espanha, atraídos pelo sol e pela cultura, mas também em busca de uma segurança que eles afirmam não encontrar mais na Turquia ou em Magreb. A TUI Berlin, grande operadora que movimenta 6,5 milhões de europeus para a Espanha a cada ano, não registrou cancelamentos. (TUBELLA et al., 2017).

Outros trechos da matéria publicada pelo portal virtual do jornal El País, o qual classifica como rigorosos os jornais ingleses The Guardian e The Independent, permitem identificar a linha de abordagem dessas duas publicações, que se alinharam ao tratar a questão a partir da análise dos efeitos nocivos do turismo de massa e a necessidade de repensar o modelo.

Tal afirmação do jornal El País encontra respaldo no que dizem Sodré, (2006 p. 20) a respeito dos meios que fazem parte do mecanismo de produção dos sentidos. Ela também se relaciona ao exposto por Lafon (2019) em relação as interações sociais midiatizadas, que ao conferirem visibilidade a determinadas posições e opiniões, refletem em todos os domínios do cotidiano. Assim contribuem para a estruturação do modo de pensar e conduzir certas práticas que englobam questões de cunho social.

Ao relacionar tais conceitos com o contexto do fragmento retirado da reportagem, nota-se que o enfoque das escolhas editoriais de mídias inglesas em torno da turismofobia e dos "efeitos nocivos do turismo de massa", podem gerar implicações que caminham 
junto à propagação de discursos e noticiários inflamados, tendenciosos, alimentando o ambiente hostil entre moradores e turistas.

Portanto, percebe-se que a partir da abordagem de três narrativas diferentes, os impactos econômicos do turismo são mais sentidos nos âmbitos local, regional e nacional, influenciando em diversas circunstâncias a qualidade de vida dos moradores. Entretanto, na visão dos próprios turistas e agências de viagem estrangeiros, a atratividade da destinação não é afetada, e os sinais de turismofobia na Espanha não apresentam alto grau de relevância para potenciais viajantes.

Conforme Murta e Albano (2002) o turismo como parte importante para o pleno desenvolvimento do setor econômico demanda estratégia e responsabilidade no que diz respeito ao cotidiano das comunidades receptoras.

As matérias do jornal El País, ao refletirem os aspectos da turismofobia junto aos impactos econômicos nas realidades citadas, demonstraram o papel fundamental de diretrizes sociopolíticas de planejamento e monitoramento fiscal. A atenção voltada para os investimentos a longo prazo que incluam a população local é crucial para que a mesma possa usufruir dos reflexos positivos da atividade turística e participar do processo de tomada de decisões.

\section{CONSIDERAÇÕES FINAIS}

Os discursos e as narrativas midiáticas agem como grandes influenciadores acerca do processo de expansão das mudanças socioculturais e à formação do modo de pensar, viver, agir, e especialmente no que está relacionado à promoção da atividade turística. Em virtude da massificação dos meios de comunicação, a sociedade contemporânea passa a estruturar-se com base nos sentidos de outrem. Reproduz-se, de certa forma, a "ilusão da verdade", na medida em que os sujeitos sociais passam a se orientar por visões e concepções baseadas no modus operandi midiático.

Neste sentido, o objetivo deste trabalho consistiu em discutir as representações midiáticas do termo "turismofobia" nos discursos sobre os impactos econômicos do turismo identificados a partir de publicações do jornal espanhol El País que abordam a temática, no período de julho e agosto de 2017. 
Pode-se verificar que a ideia da terminologia "turismofobia" teve seu ponto de partida em meados do ano de 2008, por meio de outro neologismo que também repudia os excessos de turismo numa localidade, a chamada "turistificação". Nos discursos do veículo analisado, o jornal espanhol El País, apropriou-se do termo "turismofobia", passando a incorporá-lo em suas reportagens para diversificar as representações do destino turístico, influenciando assim as emoções e imagem que o leitor possui a respeito de Barcelona e outras cidades espanholas. Em muitas das narrativas jornalísticas apresentadas, é recorrente o termo sendo relacionado ao caráter especulativo e pejorativo da atividade turística. Notou-se que os editorais do El País trazem a "turismofobia" como o agente determinante - e por vezes isolado - dos atuais conflitos sociais, econômicos e atos hostis de moradores para com os visitantes.

Grande parte das narrativas apresentam depoimentos de moradores de Barcelona e arredores que relatam os impactos econômicos decorrentes da prática desregulada de atividades relacionadas ao turismo, com a perspectiva direcionada à especulação imobiliária, escassez de serviços e infraestrutura, além do sentimento de demérito da cultura local. A "turismofobia" no ano de 2017, segundo a leitura das reportagens publicadas no jornal El País, apresenta-se como um constructo popularizado por meios de comunicação, em especial, com a finalidade mais evidente de nutrir conflitos existentes em Barcelona que podem estar relacionados a outros fatores: sociais, comportamentais, políticos e quiçá ideológicos. Explorou-se tais situações, nas quais uma definição equivocada ou errônea de "turismofobia" pôde provocar reações que, por sua vez, deram lugar a comportamentos que acabaram fazendo com que a definição baseada na lógica da mídia se estabelecesse, tornando o assunto de grande interesse público.

Assim, as lacunas existentes em torno dos constructos sobre a "turismofobia" são perceptíveis, considerando que o termo pode surgir e desaparecer das discussões midiáticas em curto espaço de tempo, em virtude das alterações nas pautas da própria mídia em suas abordagens ligadas ao turismo. Contudo, para o campo da reflexão acadêmica, são necessárias a sistematização e a observação das informações referentes ao termo, bem como suas repercussões na sociedade. O ruído, sobretudo midiático, da turismofobia, tem desencadeado debates nos principais meios de comunicação e nas esferas acadêmico-científica do turismo e das ciências humanas em geral, acirrando as 
disputas já existentes em locais turísticos, entre moradores locais e turistas, sem que se perceba a vocalização de outros atores sociais nesse processo, como os empresários.

A reflexão desenvolvida neste trabalho pretende contribuir para o pensamento crítico a respeito das conceituações empregadas pela esfera acadêmica a partir da categorização dos impactos turísticos. Contudo, é necessário também avançar os estudos sobre a utilização de fontes midiáticas, pois no contexto atual é nesse espaço em que as rivalidades, opiniões e os novos padrões de consumo são expressos. Por fim, a contribuição do estudo consiste no contínuo entendimento dos efeitos que a midiatização e a turismofobia podem causar nas percepções sociais, bem como alertar sobre os aspectos que concernem ao turismo de massa em localidades onde a atividade turística está em pleno desenvolvimento.

Dada a seleção das reportagens ter sido em curto espaço de tempo, não foi possível observar, por exemplo, a evolução ou as mudanças na abordagem da turismofobia no $E l$ País. Do mesmo modo não foi o objetivo deste trabalho averiguar as percepções dos leitores do jornal El País a partir dos conteúdos analisados sobre a turismofobia. Estas abordagens recomendadas para pesquisas futuras, a fim de compreender de que forma suas opiniões sobre as localidades abordadas têm sido influenciadas.

O estudo da "turismofobia" atrelado ao ruído midiático revela-se um campo de investigação que pode ser frutífero nas pesquisas junto aos destinos em fase de consolidação no mercado turístico brasileiro, considerando-se os sinais crescentes de "turismofobia" ao redor do mundo.

\section{REFERÊNCIAS}

BENI, M. C. Análise estrutural do turismo. 12.ed.rev.atual. São Paulo: Ed. SENAC, 2007.

CALA, A; URBANO, P. M; FERNANDÉZ, J. I. P. Estructura económica del turismo. Madri: Editorial Síntesis, 2006.

CONGOSTRINA, A. L. "Ahora frenamos aquellos excesos”. EI País.com, Barcelona, 05 ago.2017.Cataluña.Disponível em:<https://elpais.com/ccaa/2017/08/05/catalunya/1501952071_342014.html >. Acesso em: 04 ago. 2018.

COOPER, C. et al. Turismo: princípios e práticas. Porto Alegre: Ed. Bookman, 2007. 
DOMÍNGUEZ, A. Q. Turismofobia, ou o turismo como fetiche. Revista do centro de pesquisa e formação. Edição Especial: Ética no Turismo. SESC. São Paulo, 2018. p. 22-30.

EL PAÍS. ¿Turismofobia o empleofobia? El País.com, 31 jul. 2017. Opinión.

Disponível em:

$<$ https://elpais.com/elpais/2017/07/31/opinion/1501519982_750004.html>. Acesso em: 04 ago. 2018.

Turismo amenazado. El País.com, 27 ago. 2017. Opinión. Disponível em:

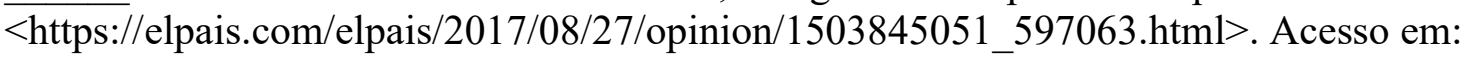
04 ago. 2018.

FALCO, D. de P. Narrativas turísticas: imaginário e mídia na experiência urbana do turismo. Revista Rosa dos Ventos, Caxias do Sul, v.3, n.1, 2011.

GOOGLE TRENDS. Turismofobia, 2017. Disponível em:

$<$ https://trends.google.com.br/trends/explore?date=2017-01-01\%202017-

$1231 \&$ geo $=$ ES\&q=turismofobia $>$. Acesso em: 25 set. 2018.

GOMES, P. G. Dos Meios à Midiatização. São Leopoldo: Ed. Unisinos, 2017.

JAFARI, J. Encyclopedia of tourism. Londres: Routledge, 2000.

JURDAO, A.F. Los mitos del turismo. Madri: Endymion, 1992.

LAFON, B. (Org.). Médias et médiatisation: analyser les médias imprimés, audiovisuels, numériques. Fontaine: PUG, 2019.

MICHAELIS, 2018. Disponível em: $<$ http://michaelis.uol.com.br/modernoportugues/busca/portugues-brasileiro/fobia/>. Acesso em: 24 abr. 2018.

MILANO, C. Overtourism and Tourismphobia: Global trends and local contexts. Barcelona: Ostelea School of Tourism \& Hospitality, 2017.

MURTA, S. M; ALBANO, C. Interpretar o patrimônio: um exercício do olhar. Belo Horizonte: Ed UFMG, 2002.

ORGANIZAÇÃO MUNDIAL DO TURISMO. Compilation of UNWTO

Declarations, 1980 - 2018. Madri: OMT, 2019. Disponível em: <https://www.eunwto.org/doi/pdf/10.18111/9789284419326>. Acesso em: 01 fev. 2020.

PAIVA, C. C. de. Sob o signo de Hermes, o espírito mediador: midiatização, interação e comunicação compartilhada. In: MATTOS, M. Â; JANOTTI, J. J; JACKS, N. (Orgs.). Mediação \& Midiatização. Salvador: EDUFBA, 2012, p. 149-170. 
QUINTANA, V. M. Ocio y turismo en la sociedad actual: Los viajes, el tiempo libre y el entretenimiento en el mundo globalizado. Madri: McGraw Hill, 2006.

RUIZ, D. M. Turistofobia. El País.com, 12 jul. 2008. Cataluña. Disponível em: $<$ https://elpais.com/diario/2008/07/12/catalunya/1215824840_850215.html >. Acesso em: 04 ago. 2018.

SODRÉ, M. Antropológica do espelho: Uma Teoria da Comunicação Linear e em Rede. Petrópolis, RJ: Ed.Vozes, 2002.

. Eticidade, campo comunicacional e midiatização. In: MORAES, D. (Org.). Sociedade midiatizada. Rio de Janeiro: Mauad, 2006, p. 19-31.

SWARBROOKE, J. Turismo sustentável: meio ambiente e economia. São Paulo: Ed. Aleph, 2000.

TUBELlA, P; CARBAJOSA, A; SÁNCHEZ, Á. Inquietud en el Reino Unido ante los brotes de turismofobia en España. EI País.com, Londres; Berlim; Bruxelas; Paris, 13 ago. 2017. España. Disponível em:

$<$ https://elpais.com/politica/2017/08/11/actualidad/1502461601_981172.html >. Acesso em: 04 ago. 2018.

Recebido em: 20-10-2019

Aprovado em: 27-03-2020 